\title{
(a) catanon \\ () \\ OPEN ACCESS \\ Atypical dysphagia with end-stage oesophageal disease 30 years post Angelchik device placement in a 72-year-old man
}

\author{
Mattan Arazi, ${ }^{1,2}$ Brian Vadasz, ${ }^{1}$ Benjamin Person, ${ }^{1,3}$ Ronen Galili, ${ }^{1,2}$ Jason Lefkowitz ${ }^{1}$
}

${ }^{1} T$ The Ruth and Bruce Rappaport Faculty of Medicine, Technion Israel Institute of Technology, Haifa, Israel

${ }^{2}$ Department of Cardiothoracic Surgery, Carmel Medical Center, Haifa, Israel

${ }^{3}$ Department of Surgery 'A', Carmel Medical Center, Haifa, Israel

\section{Correspondence to}

Dr Jason Lefkowitz;

J.J.Lefkowitz@gmail.com

Accepted 11 November 2019

Check for updates

(c) BMJ Publishing Group Limited 2020. Re-use permitted under CC BY-NC. No commercial re-use. See rights and permissions. Published by BMJ.

To cite: Arazi M, Vadasz $B_{\text {, }}$ Person B, et al. BMJ Case Rep 2020;13:e230736. doi:10.1136/bcr-2019230736

\section{SUMMARY}

Here we describe an atypical presentation of progressive dysphagia in a 72-year-old man leading to frequent regurgitations over the course of 30 years. Investigations revealed a foreign body ring surrounding the proximal stomach and dilation of the oesophagus proximal to the gastro-oesophageal junction. An Angelchik device was extracted; however, the patient's rapid deterioration prior to surgery, in addition to his severely dysfunctional oesophagus, required placement of a jejunostomy feeding tube. Device removal was complicated by prior abdominal surgery, necessitating a thoracic approach. This case offers guidance on the management of patients with Angelchik prostheses who develop similar complications, while drawing attention to the importance and difficulties of early, definitive diagnosis in oesophageal pathology such as achalasia and gastrooesophageal reflux disease.

\section{BACKGROUND}

The Angelchik device (AD), a ring-like silicone prosthesis placed around the lower oesophagus below the diaphragm, was first described in 1979 by Angelchik and Cohen ${ }^{1}$ as a 'simple and safe' solution for sliding oesophageal hiatal hernia and gastro-oesophageal reflux disease (GERD). Greater than 25000 of such devices were placed in the early 1980s. ${ }^{2}$ At the time it was unknown how AD prevents reflux. ${ }^{3}$ One study suggested that the device prevents unfolding of the lower gastrooesophageal sphincter during increased gastric pressure. $^{4}$ Following a randomised prospective study in $1989^{5}$ which confirmed increasing reports of complications, including strap malfunction, device migration, oesophageal erosion and severe dysphagia, AD placement was abandoned ${ }^{2}$ by the late 1990 s, in favour of Nissen's fundoplication. ${ }^{6}$

\section{CASE PRESENTATION}

A 72-year-old man, a US expatriate and veteran, presented to our emergency department with chronic regurgitation and weight loss of $35 \mathrm{~kg}$ over 2 months. He has an extensive history of smoking and alcohol use from teenage to age 45 , in addition to an unspecified traumatic event to the upper abdomen during military service. Records prior to his immigration to Israel were unavailable, and most of the medical history was obtained directly from the patient. In 1983, he underwent placement of an $\mathrm{AD}$ due to recurrent episodes of coughing and vomiting; the diagnosis at the time was unspecified. He underwent two additional operations, one immediately after the first placement and another within weeks of the second, due to two separate migrations of the ring into the abdominal cavity. Recently, the patient has complained of recurrent episodes of dysphagia and regurgitation that have rapidly worsened over 2 months, in which time he did not pass stool, but had passed flatus per rectum.

In the emergency department the patient was haemodynamically stable. Physical examination demonstrated significant weight loss and malnourishment. He was admitted under the general surgery team.

\section{INVESTIGATIONS}

Laboratory values revealed haemoglobin of $130 \mathrm{~g} / \mathrm{L}$, leucocytosis of $16.5 \times 10^{9} / \mathrm{L}, \mathrm{C}$ reactive protein of $1.43 \mathrm{mg} / \mathrm{L}$, creatinine of $1.3 \mathrm{mg} / \mathrm{dL}$, potassium of 5.2 $\mathrm{mEq} / \mathrm{L}$ and albumin of $3.2 \mathrm{~g} / \mathrm{dL}$. Both Carcinoembryonic Antigen $(3.2 \mathrm{ng} / \mathrm{mL})$ and Carbohydrate Antigen 19-9 (22.6 U/mL) tumour markers were within normal limits. A non-contrast CT scan of the abdomen revealed a hiatal hernia with a foreign body ring surrounding the proximal stomach with marked distention of the oesophagus proximal to the gastro-oesophageal junction (figure 1). The CT scan was negative for primary tumours elsewhere. Endoscopic investigation demonstrated an oesophagus full of solid content, with the entire distal oesophagus oedematous with congested mucosa. Biopsies of this region demonstrated intestinal-type mucosa with chronic inflammation, adenomatous changes, low-grade dysplasia and fibrosis. A barium swallow study demonstrated significant dilatation of the oesophagus, locating the proximal stomach to the mediastinum (figure 2).

\section{TREATMENT}

To improve his nutritional status, a double-lumen 5 -French peripherally inserted central catheter was inserted and the patient received parenteral nutrition (TPN), in addition to Ensure nutritional supplements. Following 2 weeks of TPN, he continued to have significant weight loss. A decision was made to remove the $\mathrm{AD}$. Considering his surgical history, there was concern regarding an abdominal approach due to possible adhesions and difficulty in retrieving the prosthesis. Therefore, a 


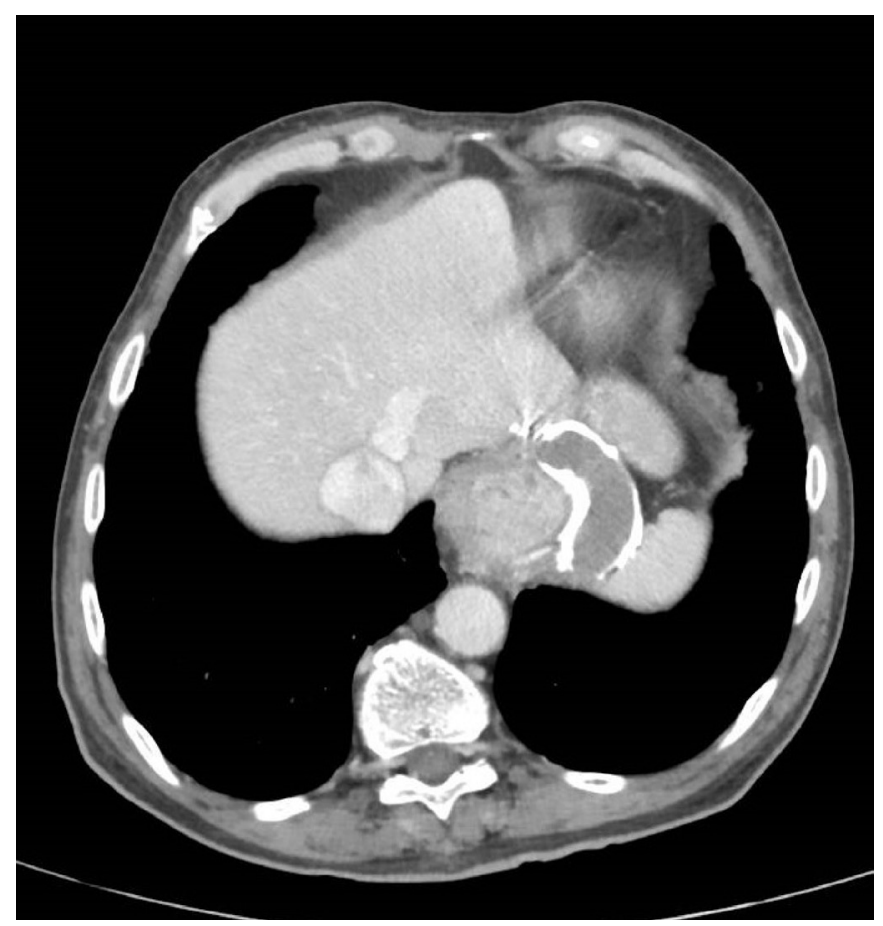

Figure 1 Non-contrast CT showing the Angelchik device with distention of the oesophagus.

left anterolateral thoracotomy between the seventh and eighth ribs was planned. Preoperative evaluation included transoesophageal echocardiogram, X-ray angiography and high-resolution CT. Intraoperatively, the oesophagus appeared fibrotic with adhesions and markedly distended throughout its entire length.

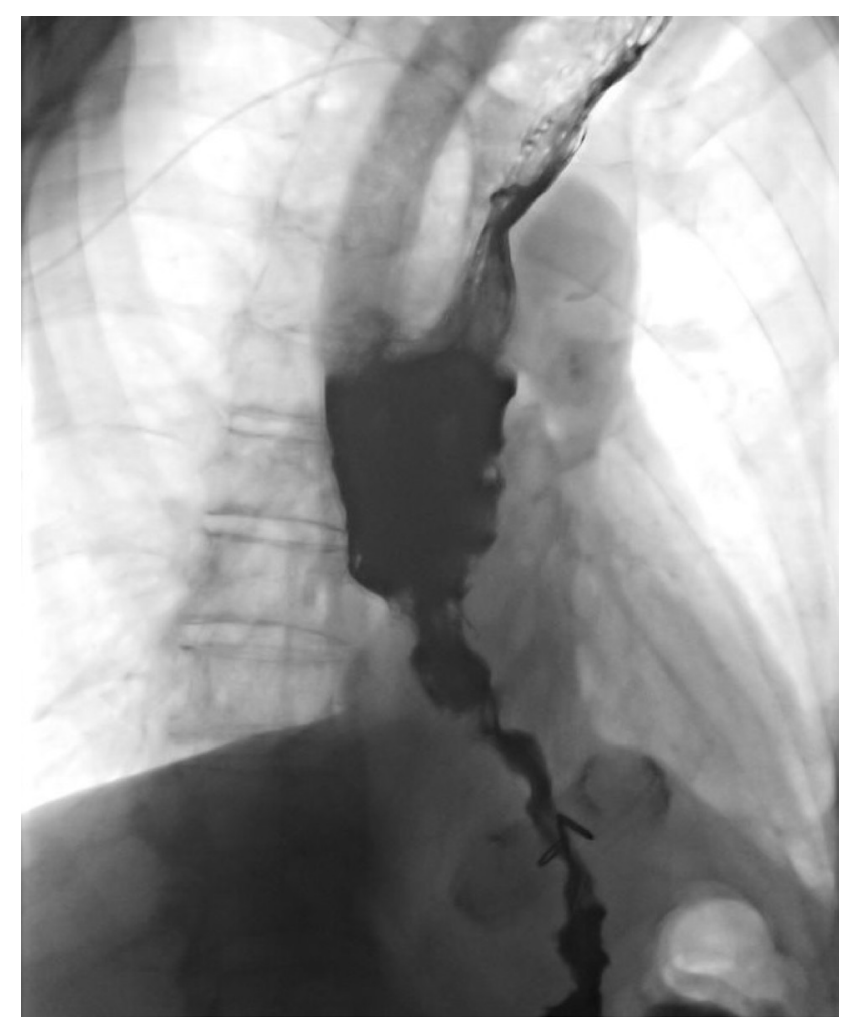

Figure 2 Barium swallow demonstrating the dilated proximal stomach and delayed emptying of the oesophagus.

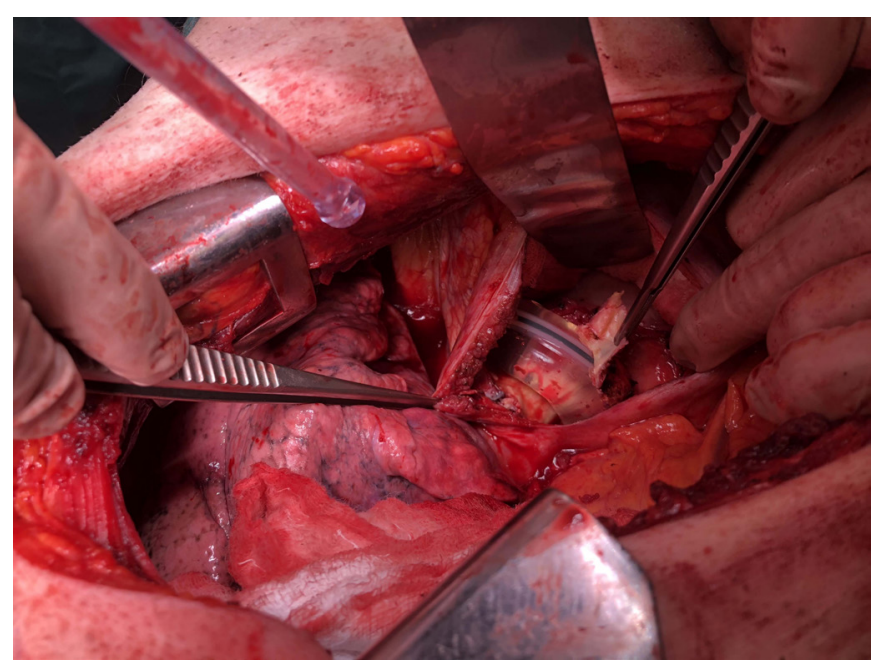

Figure 3 Intraoperative image of the Angelchik device below the diaphragm.

A radial incision of the diaphragm was performed, and an intact $\mathrm{AD}$ was seen completely encased in fibrotic, calcified tissue (figure 3). The ring was held in place with several metallic clips at its anterior aspect. The spleen and left lobe of the liver were adherent to the fibrotic tissue. The stomach appeared normal on its exterior. Adhesiolysis, excision of the fibrotic tissue and retrieval of the intact $\mathrm{AD}$ (figure 4) were performed, followed by removal of the calcified metallic clips. A nasogastric tube and abdominal and thoracic drains were placed, and the patient was transferred to the intensive care unit (ICU).

\section{OUTCOME AND FOLLOW-UP}

Following transfer to the surgery department from the ICU, the patient developed a fever of $38.7^{\circ} \mathrm{C}$ and tachycardia due to culture-positive candidemia. The catheter was replaced, and the patient was started on intravenous caspofungin treatment. Transthoracic echocardiogram and ophthalmological examinations were performed in suspicion of acute endocarditis; however, both were unrevealing. A CT of the chest revealed a non-specific opacity in both lungs. Two weeks following the surgery, the patient was unable to swallow liquids. In addition, despite increased rates of TPN infusion, the patient continued

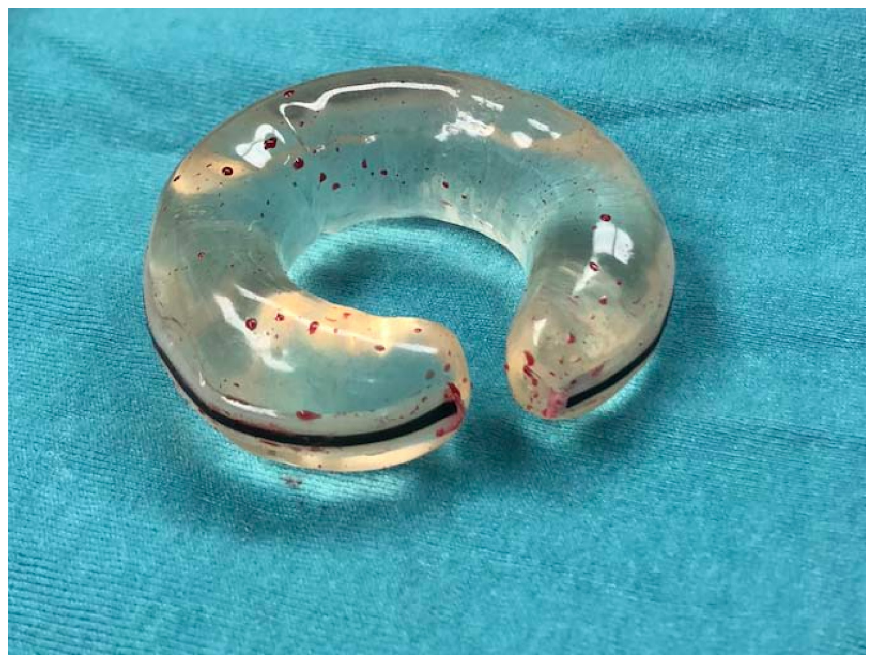

Figure 4 Angelchik prosthesis removed. 
to lose weight. Therefore, he underwent placement of a jejunostomy feeding tube (J-tube) for enteral nutritional support. At the time of the surgery, an oesophagogastroduodenoscopy with biopsy was performed to assess for possible adenocarcinoma, with negative results. He was discharged following resolution of his candidemia infection. Follow-up surgery for oesophageal reconstruction was discussed with the patient.

Three months later he was seen in the emergency department for haemodynamic instability due to an unknown cause. Attempts were made to resuscitate him but were unsuccessful.

\section{DISCUSSION}

Here we present a rare case of dysphagia that has progressed to end-stage oesophageal disease in a 72-year-old man who has been living with $\mathrm{AD}$ for 30 years. Below we discuss our patient's oesophageal disease in comparison with typical AD-associated complications as reported in the literature. Given the atypical presentation, we consider at least one other possibility, of endstage oesophageal disease due to untreated achalasia rather than what was thought to be intractable GERD over 30 years.

\section{Complications and removal of $A D$}

Introduced in $1979, \mathrm{AD}$ was thought to be a safe alternative for controlling refractory GERD and treating hiatal hernia when fundoplication was too difficult. ${ }^{1}$ Dysphagia is the most common complication seen in $\mathrm{AD}$ patients, ranging from self-limited postoperative dysphagia to chronic intermittent or progressive dysphagia. ${ }^{27}$ The dysphagia seen in $\mathrm{AD}$ patients may be due to overtightening of the device around the oesophagus, obstructing food passage. ${ }^{8}$ The formation of a fibrous capsule adherent to the surrounding structures, possibly due to an exaggerated inflammatory response, could also contribute to dysphagia. ${ }^{8} 10$ This fibrous capsule was seen intraoperatively in our patient during the removal of the $\mathrm{AD}$. Other reported complications included migration of the device, erosion through the oesophagus, fistula formation and the development of adenocarcinoma proximal to the $\mathrm{AD} .^{781011}$ Specifically, our patient developed end-stage oesophageal disease with a complete inability to swallow, necessitating the placement of a J-tube to allow for enteral nutritional support. To our knowledge, this is the first report in the literature describing this serious, long-term complication of $\mathrm{AD}$ placement.

Due to its high complication rate, many patients underwent removal of the AD. ${ }^{271213}$ Recent literature has reported successful removal of AD laparoscopically. Underwood et $\mathrm{al}^{13}$ described the resolution of dysphagia in a patient who continued to have only mild reflux symptoms following laparoscopic removal of AD. Another case reported by Carbonell and Maher ${ }^{12}$ described the removal of the $\mathrm{AD}$ via a laparoscopic, transgastric approach to retrieve an $\mathrm{AD}$ that had eroded through the gastrointestinal junction. Jalil et $a l^{14}$ described the laparoscopic removal of Angelchik prosthesis followed by an immediate Nissen's fundoplication in a patient who had an AD for over 20 years. ${ }^{14}$ Others have demonstrated successful endoscopic removal of AD that had eroded through the oesophagus or created a fistula. ${ }^{811}$ Fewer reports, however, have demonstrated the removal of $\mathrm{AD}$ via a thoracotomy. Battaglini et $a l^{15}$ described a case of a patient who developed severe, prolonged dysphagia following insertion of $\mathrm{AD}$ that caused angulation of the gastro-oesophageal junction with subsequent obstruction. A left posterolateral thoracotomy was performed, and the prosthesis was delivered through the hiatus. In contradiction to our patient, the patient described had a normal postoperative period with normal oesophageal emptying seen on barium swallow following Belsey Mark IV antireflux J-tube. Overall, this fact highlights that transthoracic approach is a unique and excellent alternative to removal of $\mathrm{AD}$ when there are associated complications. ${ }^{15}$

\section{Early signs and symptoms of oesophageal pathology}

Early and definitive diagnosis of oesophageal pathology is critical to avoid long-term consequences, including oesophageal cancer and progression to end-stage oesophageal disease. In the presented case, there was no definitive diagnosis for the patient's original dysphagia. He underwent AD placement in 1983 to treat his symptoms which were consistent with GERD. The early stages of achalasia, however, are easily confused with GERD, mainly due to misinterpretation of typical clinical features such as dysphagia, heart burn and regurgitation, and complicated by the fact that endoscopy and radiology are frequently normal. ${ }^{16}$ Hence patients are often treated for other disorders including GERD before the diagnosis of achalasia is established. ${ }^{16}$ Therefore, patients with refractory GERD should undergo oesophageal manometry to exclude motility disorders such as achalasia, which is managed differently from reflux disease. ${ }^{17} 18$

In a recent 2-hour interview with the patient, he described, in the few years prior to his $\mathrm{AD}$ placement, frequent episodes of intermittent, severe coughing spells which regularly induced vomiting and occasional haematemesis. He also described a need to artificially induce vomiting after meals. Moreover, he noted that in 1992, almost 10 years post-AD placement, he had completed a barium swallow study in Israel, the results of which 'showed slow passage of a sandwich [food bolus] which eventually stopped for more than 10 min mid-esophagus'. In the same study, he describes the slow passage of liquid that had eventually passed through the gastro-oesophageal junction.

In susceptible individuals, both operative and non-operative trauma can damage surrounding vagal nerve structures, leading to a clinical picture of achalasia. ${ }^{19} 20$ During our patient's military service in the late 1970s, he sustained an unspecified traumatic event to the upper abdomen which required surgical treatment.

Taken together, these symptoms and signs certainly raise suspicion of achalasia, possibly as an original diagnosis.

The cause of his dysphagia is still unknown and may result from multiple aetiologies. Other potential causes for his rapid weight loss, such as adenocarcinoma of the oesophagus or colon, were excluded. We raise the consideration that the progression to end-stage oesophageal disease presented here could alternatively

\section{Learning points}

- The Angelchik device (AD), a silicone prosthesis once thought to treat gastrointestinal reflux and hiatal hernia, may lead to intractable dysphagia and end-stage oesophageal disease, in addition to other complications.

- Potentially thousands of patients worldwide still harbour an $A D$ which may require removal.

- The possibility of paraneoplastic achalasia should be ruled out before proceeding with surgery, especially in patients with strong risk factors such as tobacco and alcohol.

- Open thoracotomy is an excellent alternative for removal of $A D$ when other methods prove too difficult.

- Signs and symptoms of oesophageal pathologies such as achalasia and gastro-oesophageal reflux disease often overlap, making early and definitive diagnosis difficult. 
be explained by lack of appropriate treatment for achalasia over the course of 30 years.

\section{Case significance}

This case highlights a specific population that may still have AD and in addition may be suffering from its associated complications. Knowledge of $\mathrm{AD}$ and its associated complications may guide future management of AD patients and those alike.

Acknowledgements The authors acknowledge Firas Darawasha, Thoracic Surgery Resident, Department of Cardiothoracic Surgery, Carmel Medical Center; and the Ruth and Bruce Rappaport Faculty of Medicine, Technion Israel Institute of Technology, Haifa, Israel.

Contributors $M A, B V, B P, R G$ and JL made substantial contributions to the conception or design of the work, or the acquisition, analysis or interpretation of data. MA, BV, BP, RG and JL contributed to drafting the work or revising it critically for important intellectual content. Final approval of the version published was obtained from all authors. All authors agree to be accountable for all aspects of the work in ensuring that questions related to the accuracy or integrity of any part of the work are appropriately investigated and resolved. MA and JL wrote the manuscript.

Funding The authors have not declared a specific grant for this research from any funding agency in the public, commercial or not-for-profit sectors.

Competing interests None declared.

Patient consent for publication Obtained.

Provenance and peer review Not commissioned; externally peer reviewed.

Open access This is an open access article distributed in accordance with the Creative Commons Attribution Non Commercial (CC BY-NC 4.0) license, which permits others to distribute, remix, adapt, build upon this work non-commercially, and license their derivative works on different terms, provided the original work is properly cited and the use is non-commercial. See: http://creativecommons.org/ licenses/by-nc/4.0/.

\section{REFERENCES}

1 Angelchik JP, Cohen R. A new surgical procedure for the treatment of gastroesophageal reflux and hiatal hernia. Surg Gynecol Obstet 1979;148:246-8.
2 Maxwell-Armstrong CA, Steele RJ, Amar SS, et al. Long-Term results of the Angelchik prosthesis for gastro-oesophageal reflux. Br J Surg 1997;84:862-4.

3 Lee JR, Temple JG. The Angelchik prosthesis behaves as a fundoplication. Ann R Coll Surg Engl 1993:75:90-3.

4 Bonavina L, DeMeester T, Mason R, et al. Mechanical effect of the Angelchik prosthesis on the competency of the gastric cardia: pathophysiologic implications and surgical perspectives. Dis Esophagus 1997;10:115-8.

5 Stuart RC, Dawson K, Keeling P, et al. A prospective randomized trial of Angelchik prosthesis versus Nissen fundoplication. Br J Surg 1989;76:86-9.

6 Yadlapati R, Hungness ES, Pandolfino JE. Complications of antireflux surgery. Am J Gastroenterol 2018:113:1137-47.

7 Varshney S, Kelly JJ, Branagan G, et al. Angelchik prosthesis revisited. World J Surg 2002;26:129-33.

8 Florez DA, Howington JA, Long JD. Esophageal obstruction secondary to erosion of an Angelchik prosthesis: the role of endoscopic management. Gastrointest Endosc 2003;58:624-6.

9 Robertson CS, Smart H, Amar SS, et al. Oesophageal transit of marshmallow after the Angelchik procedure. Br J Surg 1989;76:245-7.

10 Shetty VD, Thrumurthy SG, Pursnani KG, et al. Angelchik prosthesis with oesophageal adenocarcinoma: our surgical approach. Annals 2010;92:e64-8.

11 Pence MM, Hubbard M, Singla MB, et al. Esophagogastric fistula caused by an Angelchik antireflux prosthesis. ACG Case Rep J 2015;2:213-5.

12 Carbonell AM, Maher JW. Laparoscopic transgastric removal of an eroded Angelchik prosthesis. Am Surg 2006:72:724-6.

13 Underwood RA, Weinstock LB, Soper NJ, et al. Laparoscopic removal of an Angelchik prosthesis. Surg Endosc 1999:13:615-7.

14 Jalil 0, Zia MK, Hassn A, et al. Laparoscopic Nissen fundoplication for the management of failed Angelchik prosthesis. J Laparoendosc Adv Surg Tech A 2011;21:77-80.

15 Battaglini JW, Schorlemmer GR, Frantz PT. Intractable dysphagia following placement of Angelchik prosthesis for reflux esophagitis. Ann Thorac Surg 1983;35:551-2.

16 Howard PJ, Maher L, Pryde A, et al. Five year prospective study of the incidence, clinical features, and diagnosis of achalasia in Edinburgh. Gut 1992;33:1011-5.

17 Garbarino S, Horton A, Patel A. The utility of esophageal motility testing in gastroesophageal reflux disease (GERD). Curr Gastroenterol Rep 2019;21:37.

18 Subramanian CR, Triadafilopoulos G. Refractory gastroesophageal reflux disease. Gastroenterol Rep 2015:3:41-53.

19 Penagini R, Cantù P, Grigolon A. Chest trauma and aetiology of achalasia. Gut 2006:55:1052.

20 Shah RN, Izanec JL, Friedel DM, et al. Achalasia presenting after operative and nonoperative trauma. Dig Dis Sci 2004;49:1818-21.

Copyright 2020 BMJ Publishing Group. All rights reserved. For permission to reuse any of this content visit

https://www.bmi.com/company/products-services/rights-and-licensing/permissions/

BMJ Case Report Fellows may re-use this article for personal use and teaching without any further permission.

Become a Fellow of BMJ Case Reports today and you can:

- Submit as many cases as you like

- Enjoy fast sympathetic peer review and rapid publication of accepted articles

- Access all the published articles

- Re-use any of the published material for personal use and teaching without further permission

Customer Service

If you have any further queries about your subscription, please contact our customer services team on +44 (0) 2071111105 or via email at support@bmj.com.

Visit casereports.bmj.com for more articles like this and to become a Fellow 